Research Paper

\title{
MicroRNA-2 I 8 Enhances the Radiosensitivity of Human Cervical Cancer via Promoting Radiation Induced Apoptosis
}

\author{
Wang Yuan ${ }^{1,2^{*}}$, Han Xiaoyun ${ }^{3 *}$, Qiu Haifeng ${ }^{4}$, Li Jing ${ }^{5}$, Hu Weixu ${ }^{6}$, Dong Ruofan ${ }^{2}$, Yu Jinjin ${ }^{2}{ }^{\bowtie}$, Shen \\ Zongji ${ }^{1}$ \\ 1. Department of Obstetrics and Gynecology, First Affiliated Hospital of Soochow University, Jiangsu Province, 215006, China. \\ 2. Department of Obstetrics and Gynecology, the Affiliated Hospital of Jiangnan University and the Fourth People's Hospital of Wuxi, Jiangsu \\ Province, 214062, China. \\ 3. Department of Gynecologic Oncology, Shandong Cancer Hospital and Institute, Shandong Province, 250117, China. \\ 4. Department of Obstetrics and Gynecology, International Peace Maternity \& Child Health Hospital of the China Welfare Institute Affiliated to \\ Shanghai Jiaotong University, Shanghai, 200030, China. \\ 5. State Key Laboratory of Oncology in South China, Sun Yat-sen University Cancer Center, Guangzhou, Guangdong Province, 510060, China. \\ 6. Department of Radiation Oncology, Zhongshan Hospital of Fudan University, Shanghai, 200032, China.
}

*The two authors contribute equally to this work.

$\triangle$ Corresponding author: Yu Jinjin, wxsyyujj@gmail.com, telephone: 0086+0510-88682116; fax: 0086+0510-85808820, the postal address: Huihe road No.200, Binhu district, Wuxi, Jiangsu Province, 214062, China. Shen Zongii, shensuzhou@163.com, telephone: 0086+0512-65700987; fax: 0086+0512-65700987, the postal address: 188 ShiZi Strees, Suzhou, Jiangsu Province, 215006, China.

(c) Ivyspring International Publisher. This is an open-access article distributed under the terms of the Creative Commons License (http://creativecommons.org/ licenses/by-nc-nd/3.0/). Reproduction is permitted for personal, noncommercial use, provided that the article is in whole, unmodified, and properly cited.

Received: 2014.02.19; Accepted: 2014.04.21; Published: 20I4.05.06

\begin{abstract}
We previously reported frequent loss of microRNA-2I8 (miR-2I8) in cervical cancer, which was associated with tumor progression and poor prognosis. As microRNAs were found invovled in the regulation of radiosensitivity in various human cancers, we therefore aim to investigate the effects of miR-2 18 on radiosensitivity of cervical cancer in the present study. The clonogenic survival assay demonstrated that loss of miR-218 could predict radioresistance in the primary cervical cancer cells $\left(R^{2}=0.6516, P<0.00 I\right)$. In vitro, abundant miR-2 18 increased the radiosensitivity in cervical cancer cells $(\mathrm{P}<0.00 \mathrm{I}$ for HeLa, $\mathrm{P}=0.009$ for $\mathrm{SiHa}, \mathrm{P}=0.016$ for $\mathrm{C} 33 \mathrm{~A}$ and $\mathrm{P}=0.0 \mathrm{l}$ for CaSki). Upregulation of miR-2 18 significantly enhanced the radiation-induced apoptosis, which was further enhanced by the combination of miR-2 18 overexpression and radiation In xenograft growth assay, combination of miR-218 overexpression and radiation notably induced cellular apoptosis and suppressed tumor growth. In conclusion, we demonstrated that miR-2/8 resensitized cervical cancer cells to radiation via promoting cellular apoptosis. Moreover, we proved that miR-2 18 as a potent predictor of radiosensitivity in cervical cancer, especially for those patients with loss of miR-2I8.
\end{abstract}

Key words: cervical cancer, miR-218, radiotherapy, sensitivity.

\section{Introduction}

Up to date, cervical cancer remains to be one of the leading gynecological malignancies worldwide. There were estimated more than 529000 new cases with cervical cancer annually in the world, and about $80 \%$ occurred in the developing countries $[1,2]$. In 2005, there were more than 58000 new cases and 20000 deaths caused by cervical cancer in the mainland of
China [3, 4]. Given that there was not a nationwide screening project yet, the incidence rate of cervical cancer might be even higher in some rural areas with poor socioeconomic status [5].

As broadly accepted, surgery and radiotherapy are still the mainly treatment for cervical cancer, and sometimes chemotherapy is performed on patients 
with recurrence or metastasis [6, 7]. The current standard radiotherapy was the combination of external beam radiotherapy and intracavitary brachytherapy, which had the same efficiency on suppressing tumor growth and inhibiting metastasis as surgery [8]. Unfortunately, several cervical cancer patients would present either intrinsic or acquired radioresistance and finally obtained poor outcomes [9]. Thus, further exploring the mechanisms underlying radioresistance is urgently required.

In the present study, using in vitro and in vivo experiments, we demonstrated that miR-218 could resensitize cervical cancer cells to radiotherapy via enhancing cellular apoptosis. Moreover, using the primary culture, we proved that miR-218 could be a potent predictor of radiosensitivity in cervical cancer patients.

\section{Materials and methods}

\section{Clinical specimens and primary culture}

This study was permitted by the Ethical Committee of our hospital and written consents were obtained from all the participants. A total of 35 fresh cervical cancer and 20 non-cancerous cervix tissues were collected from July 2010 to December 2012 in the Affiliated Hospital of Jiangnan University (Wuxi, China). The tissues were separated into two parts: one part was immediately stored in RNAlater (Qiagen, CA, USA) at $-80^{\circ} \mathrm{C}$ for miR-218 detection.

Another part was for the primary culture. Briefly, the cervical cancer tissues were rinsed twice with pre-chilled Hank's Buffered Salt Solution (HBSS, Gibco, CA, USA), and then gently minced by scalpels in the DMEM/F12 medium (Gibco) supplemented with $10 \%$ FBS (fetal bovine serum, Gibco). This mixture was then digested in the fresh medium containing $0.1 \%$ collagenase IA and $100 \mathrm{U} / \mathrm{ml}$ penicillin/streptomycin (Sigma, MN, USA) at $37^{\circ} \mathrm{C}$ for 2 hours. Then cells were washed three times and resuspended in the $1 \times$ PBS buffer (Gibco). $1 \times 10^{4}$ cells/well was seeded into the 96 well plates. After incubated at $37^{\circ} \mathrm{C}$ for 24 fours, the cells were fixed onto the Faxitron Cabinet X-ray System for irridiation with the indicated doses. The patients' information was supplied in Table 1.

\section{Cell culture and reagents}

The HeLa, SiHa, C33A and CaSki cell lines were purchased from American Type Culture Collection (ATCC, VA, USA) and cultured in DMEM/F12 with $10 \% \mathrm{FBS}$, at $37^{\circ} \mathrm{C}$ with $5 \% \mathrm{CO}_{2}$. MiR-218 mimics and its negative control were purchased form Genepharmacy Company (Shanghai, China).
Table I. Clinico-characteristics of cervical cancer patients.

\begin{tabular}{|c|c|c|}
\hline & Cervical cancer & Normal cervix \\
\hline Total number & 35 & 20 \\
\hline Median age (range) & $51.3(35-63)$ & $49.6(33-61)$ \\
\hline \multicolumn{3}{|l|}{ Stage } \\
\hline I & 17 & \\
\hline II & 9 & \\
\hline III & 6 & \\
\hline IV & 3 & \\
\hline \multicolumn{3}{|c|}{ Lymph node metastasis } \\
\hline negative & 26 & \\
\hline positive & 9 & \\
\hline \multicolumn{3}{|l|}{ Tumor size } \\
\hline$\leq 4.0 \mathrm{~cm}$ & 23 & \\
\hline$>4.0 \mathrm{~cm}$ & 12 & \\
\hline
\end{tabular}

\section{Generation of HeLa cells stably expressing miR-2 I 8}

The pGenesil-1-miR-218-expressing plasmid was established as previously described [10]. HeLa cells were transfected with the miR-218-expressing plasmids using Lipofectamine 2000 (Invitrogen, CA, USA), and G418 (400 $\mu \mathrm{g} / \mathrm{ml}$, Sigma) was used to select the clones stably overexpressing miR-218.

\section{Radiation}

A Faxitron Cabinet $X$-ray System (Faxitron, IL, USA) was used as the $\mathrm{X}$-ray source (the dose rate $=$ $0.36 \mathrm{~Gy} / \mathrm{min}$ ). The $\mathrm{X}$-rays were filtered through a $0.5-\mathrm{mm}$ aluminum filter and all the cells were treated at room temperature. Mice bearing tumor were radiated 30 minutes for totally four times (on day 0,7, 14 and 21, 10.8 Gy/each time), the lead shields were used to avoid radiation injury.

\section{MicroRNAs enrichment and TaqMan real-time PCR}

MicroRNAs were enriched using the mirVana miRNA Isolation kit (Applied Biosystems, CA, USA) according to the manufacturer's instructions. MiR-218 expression was measured using the Taqman miRNA assay kit (Applied Biosystems). U6 RNA was set as the endogenous control. The relative expression of miR-218 was calculated with the $2^{-\Delta \Delta \mathrm{Ct}}$ method. All the procedures were repeated in triplicate.

\section{Western blot}

Equal amounts of total protein (usually 20-50 $\mu \mathrm{g}$ ) were separated by $12 \%$ SDS-PAGE, then transferred onto the PVDF membrane, blocked in 5\% non-fat milk for 1 hour, and incubated with the primary antibodies overnight at $4{ }^{\circ} \mathrm{C}$. Then the membranes were incubated with an appropriate secondary antibody for 1 hour at room temperature. The bands were developed using ECL Kit (Cell Signaling Technology, Danvers, MA, USA) and quantified on a Kodak imaging sys- 
tem. The primary antibodies binding cleaved caspase 3, cleaved PARP, Rictor and GAPDH were purchased from Cell Signaling Technology.

\section{Clonogenic survival assay}

Briefly, $0.3 \times 10^{3}$ cells/well were seeded into the 6 -well plates and routinely cultured overnight. Then the cells were radiated with indicated doses $(0,2,4$ and $8 \mathrm{~Gy}$; only $4 \mathrm{~Gy}$ was given to the primary cultured cells) and further cultured for another 12 days (7 more days for the primary cultured cells). The colonies were fixed with chilled methanol and stained with crystal violet. Colonies ( $>50$ cells) were counted on an inverted microscope. The surviving fraction was calculated as follows: number of colonies/number of plated cells. All the procedures were repeated in triplicate.

\section{Apoptosis analysis}

$2 \times 10^{6}$ cells were plated into the $60 \mathrm{~mm}$ dishes and pretransfected with miR-218 mimics or negative control for 36 hours; then the cells were radiated with the dose of $2 \mathrm{~Gy}$. Twenty-four hours later, the cellular apoptosis was detected using the Annexin V-FITC Apoptosis Kit (BD Biosciences, CA, and USA). In brief, $1 \times 10^{5}$ cells were suspended in $100 \mu \mathrm{l}$ binding buffer, then $5 \mu \mathrm{l}$ PI and $10 \mu \mathrm{l}$ Annexin V-FITC were added into the solution. After incubated in dark for 15 min, another $400 \mu \mathrm{l}$ binding buffer was added into and the apoptotic statuses were detected on FACScalibur (BD Biosciences). The results were analyzed using the CellQuest software. All these procedures were repeated in triplicate.

\section{Establishment of the nude mice model bearing cervical cancer}

Six weeks old female BALB/c nude mice were used for this experiment. All animal handling procedures were performed strictly following the university Institutional Animal Care and Use Committee guidelines. The mice $(n=24)$ were randomly divided into four groups: control, miR-218 overexpression, radiation, combination of miR-218 overexpression and radiation. At first, $100 \mu \mathrm{l}\left(1 \times 10^{7}\right.$ cells $\left./ \mathrm{ml}\right) \mathrm{HeLa}$ cells with or without miR-218 overexpression were injected subcutaneously in the right posterior flank of the mice. When the tumor volume reached $100 \mathrm{~mm}^{3}$ [tumor volume $=\left(\right.$ length $\times$ width $\left.{ }^{2}\right) / 2$ ], a totally dose of 43.2 Gy (10.8 Gy/ each week) X-ray radiation were given to the mice in the latter two groups. Then the tumor was checked once a week using a caliper. On day 28 , all the mice were sacrificed and tumors were collected for further experiments.

\section{Immunohistochemical staining (IHC)}

The tumor tissues from mice were formalin-fixed and paraffin-embedded for the IHC analysis. In brief, after rehydration and antigen retrieval, the slides were incubated with primary antibodies: anti-Ki 67 (1:200, Boster Biotech Company, Wuhan, China), anti-cleaved caspase 3 (1:200, Cell Signaling Technology). The staining was visualized using DAB (Invitrogen, CA, and USA). The proliferation and apoptosis were investigated at $400 \times$ magnification. The Image $\mathrm{J}$ software was used to quantitate the percentage of Ki-67 positive cells. The staining of cleaved-caspased 3 was scored following this criterion: $0,(<10 \%$ positive); 1, (11-25\% positive); 2, (26-50\% positive); 3 , (>50\% positive).

\section{Statistical analysis}

SPSS 16.0 (SPSS Inc., USA) was used for all the statistical analysis in this study. $X^{2}$ test and t-test were appropriately applied for different types of data. $\mathrm{P}<$ 0.05 was considered to be statistically significant.

\section{Results}

\section{MiR-2 18 expression predicted the radiosensitivity of cervical cancer patients}

As shown in Figure 1A, the primary cervical cancer cells with high level of miR-218 were more sensitive to radiotherapy, while those with less miR-218 presented resistance to 4 Gy irradiation $\left(\mathrm{R}^{2}=0.6471, \mathrm{P}<0.001\right)$. Compared to the normal tissues, the expression of miR-218 was significantly downregulated in cervical cancer samples (Figure 1B, $\mathrm{P}<0.001)$. We also found much less miR-218 in all the four immortalized human cervical cancer cell lines (Figure 1B).

\section{Overexpression of $\mathbf{m i R}-2$ I 8 resensitized cervical cancer cells to radiation}

By transient transfection, we successfully elevated the level of miR-218 more than 1000 folds (Figure 1C). Simutaneously, we also detected a notably decline of the Rictor protein level (a direct target of miR-218, Figure 1D). According to our results, overexpression of miR-218 markedly increased cellular sensitivity to the $\mathrm{X}$-ray radiation especially in the $4 \mathrm{~Gy}$ group $(\mathrm{P}<0.001$ for HeLa, Figure 1E; $\mathrm{P}=0.009$ for $\mathrm{SiHa}$, Figure 1F; $\mathrm{P}=0.016$ for $\mathrm{C} 33 \mathrm{~A}$, Figure $1 \mathrm{G}$; and $\mathrm{P}=0.01$ for CaSki, Figure 1H).

\section{Overexpression of miR-2 18 enhanced radiation induced apoptosis}

As shown in Figure 2A, both miR-218 overexpression and 2 Gy radiations induced significantly apoptosis in HeLa cells, and this effect was further enhanced by the combination of miR-218 overexpression and radiation. The alterations of cleaved caspase 3 and cleaved PARP also indicated a notably increase 
of apoptosis in HeLa cells (Figure 2B). Similar results were also detected in the other three cell lines (Figure $2 \mathrm{C})$.

\section{Overexpression of $\mathrm{miR}-218$ increased radiosensitivity in vivo}

We established the HeLa cell line with stable overexpression of miR-218 (Figure 3A), and detected the same effects of miR-218 on cellular sensitivity to radiation (Figure 3B, $\mathrm{P}<0.001$ ). In the xenograft
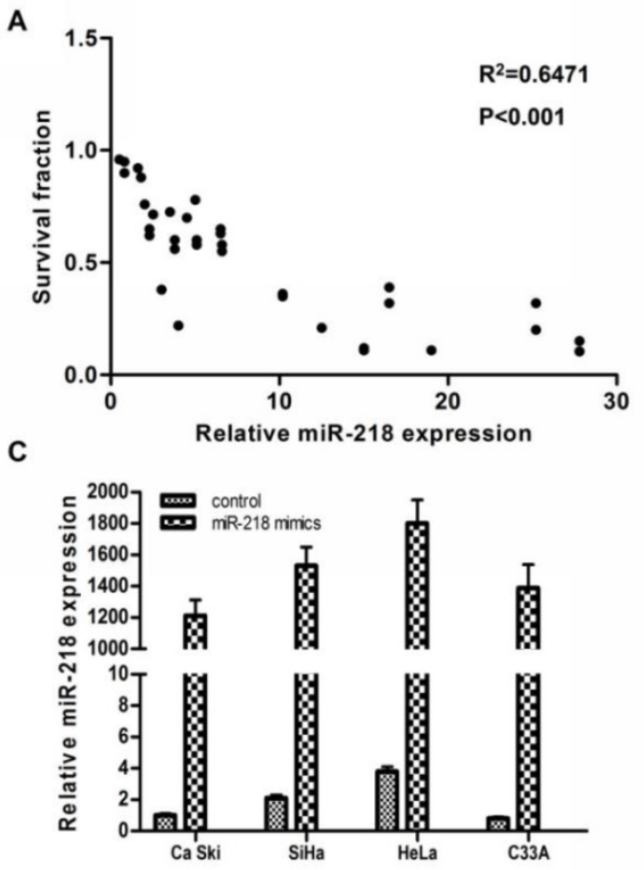

E

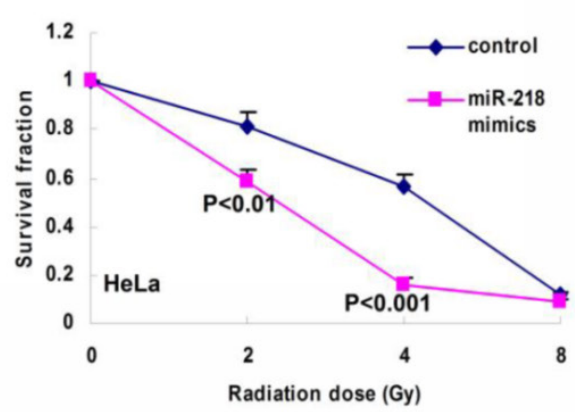

G

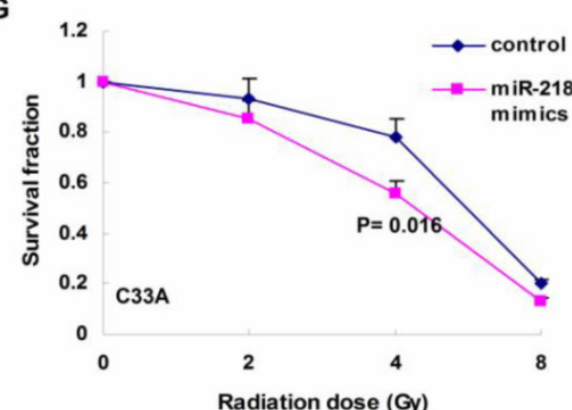

growth assay, both miR-218 overexpression and radiation suppressed tumor growth significantly $(\mathrm{P}<0.01$ and $\mathrm{P}<0.01$, respectively); and combination of these two approaches enhanced the inhibition on tumor growth (Figure $3 \mathrm{C}, \mathrm{P}<0.001$ ). According to the IHC results, the combined therapy notably blocked the expression of Ki-67 and upregulated the expression of cleaved caspase 3 (Figure 3D).

B

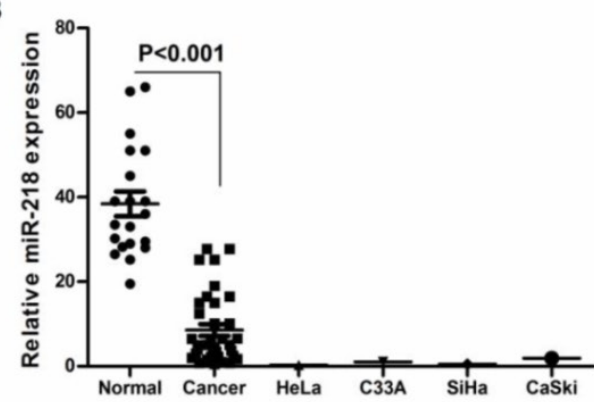

D

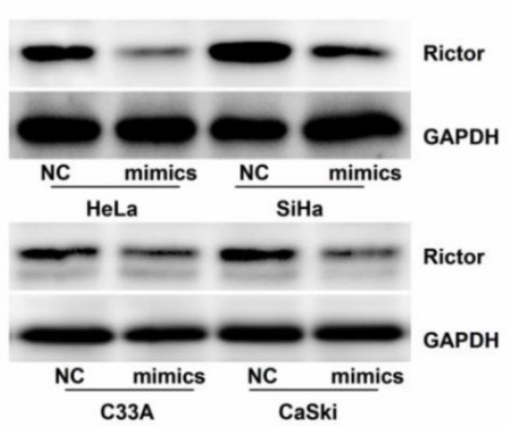

$\mathbf{F}$
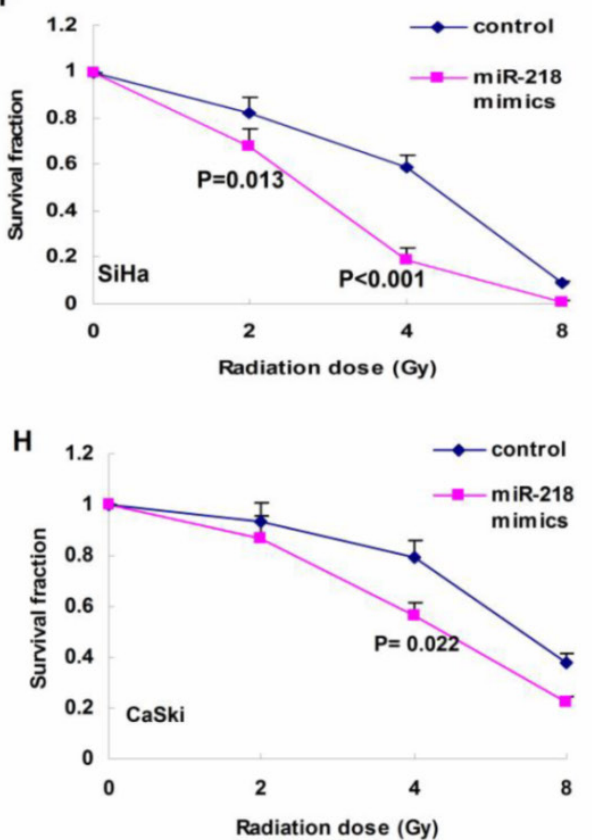

Figure I. The expression of miR-2I8 in cervical cancer. (A) high level of miR-2I8 predicted cellular sensitivity to radiation in primary cultured cervical cancer samples $\left(R^{2}=0.647 \mathrm{I}, \mathrm{P}<0.00 \mathrm{I}\right)$.Upregulation of miR-2I 8 sensitized cervical cancer cells to radiotherapy; $(\mathrm{B})$ compared to normal cervix tissues, miR-2I 8 was downregulated in human cervical cancer samples $(P<0.00 I)$, and the miR-2I 8 level was significantly low in the four human cervical cancer cell lines; $(C)$ by transient transfection, the level of miR-2I 8 was upregulated significantly in the four cells lines; (D) 48 hours after miR-21 8 transfection, we also detected notably decline of the Rictor protein (a direct target of miR-2I8); (E-H) upregulation of miR-2 18 markedly increased cellular sensitivity to the $X$-ray radiation especially in the $4 \mathrm{~Gy}$ group $(\mathrm{P}<0.00 \mathrm{I}$ for $\mathrm{HeLa}, \mathrm{P}=0.009$ for $\mathrm{SiHa}, \mathrm{P}=0.0 \mathrm{I} 6 \mathrm{for} \mathrm{C} 33 \mathrm{~A}$ and $\mathrm{P}=0.0 \mathrm{I}$ for CaSki). 
A
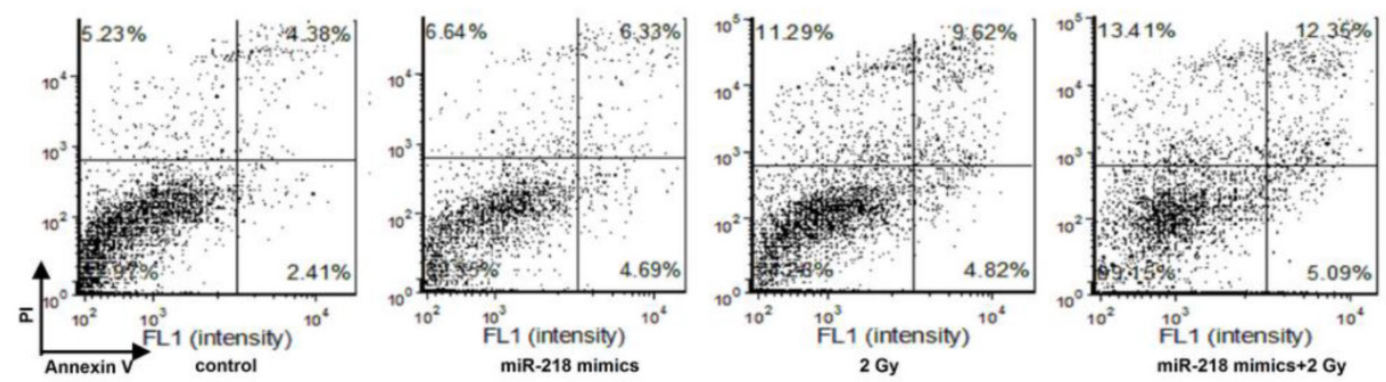

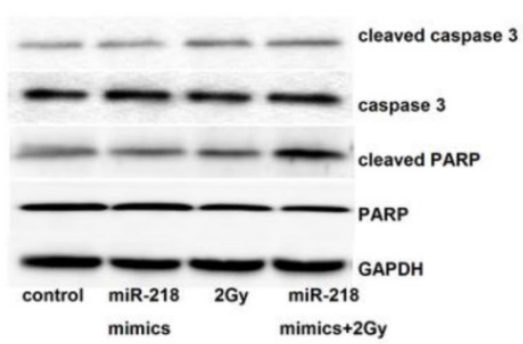

C

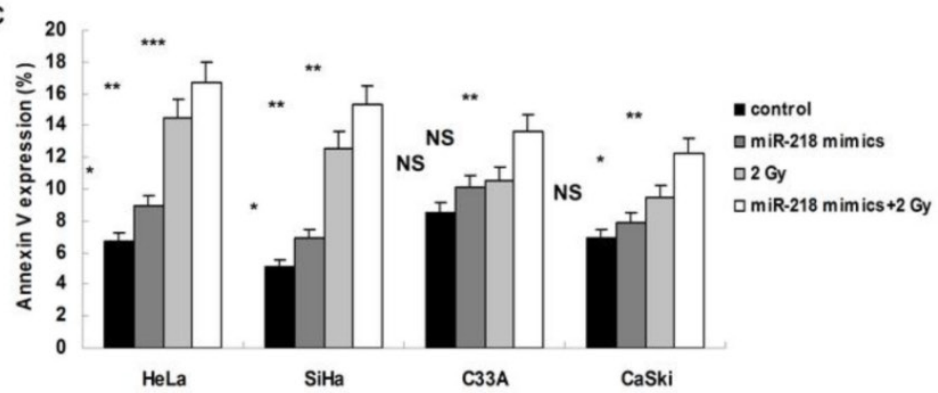

Figure 2. Upregulation of miR-218 increased radiation induced apoptosis. (A) in HeLa cells, combination of miR-218 mimics transfection and radition induced much more apoptosis than miR-218 mimics transfection alone or radiation alone; (B) both miR-218 mimics transfection and radition increased the expression of cleaved caspase 3 and cleaved PARP, the combination of the two approaches further upregulated the level of cleaved caspase 3 and cleaved PARP; (C) the combining treatment also worked well in the other three human cervical cancer cell lines (NS: not significant; *: $\mathrm{P}<0.05 ; * *: \mathrm{P}<0.01 ; * * *: \mathrm{P}<0.00 \mathrm{I})$.

A

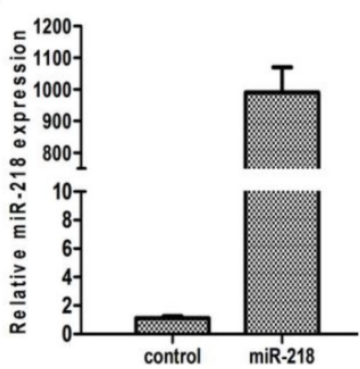

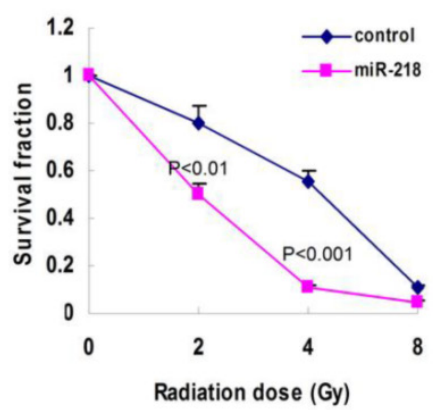

C

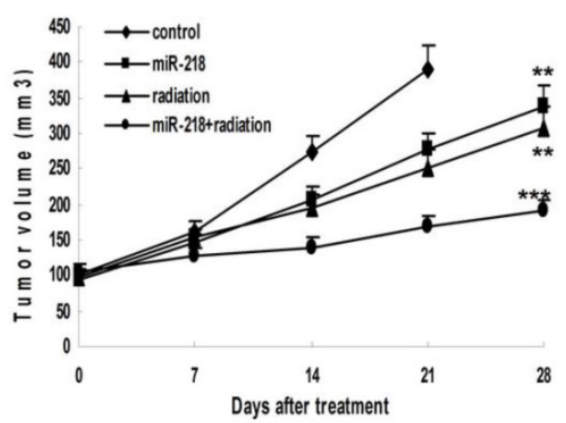

D

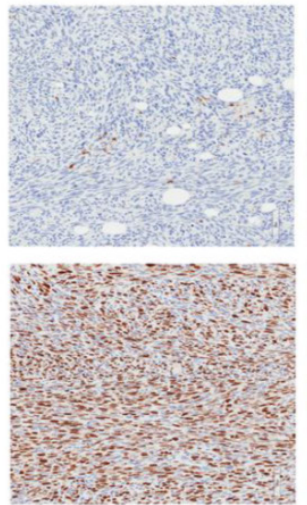

control
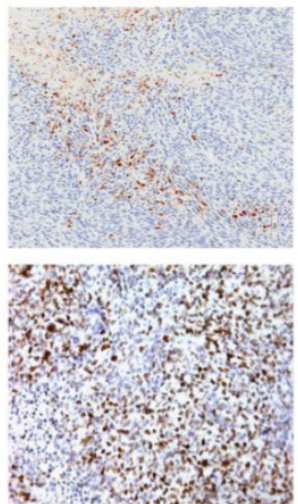

miR-218

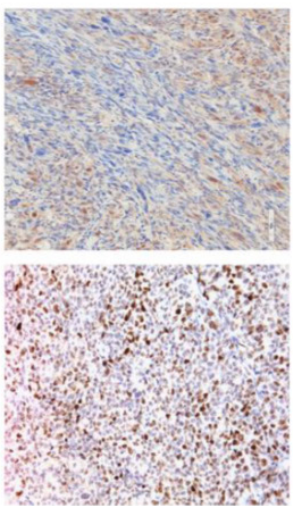

radiation
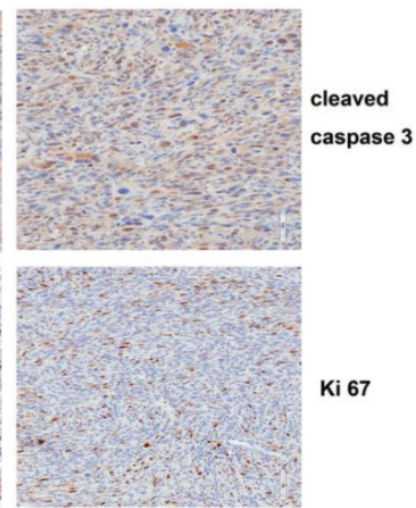

miR-218+

radiation

Figure 3. Combination of miR-2 18 overexpression and radiation suppressed tumor growth and promoted apoptosis in vivo. (A) with stable transfection, miR-2। 8 was continuously overexpressed in Hela cells; (B) abundant miR-2I 8 increased cellular radiosensitivity of HeLa cells (P<0.0I for 2 Gy and $P<0.001$ for $4 \mathrm{~Gy}$ ); (C) combination of miR-2I8 overexpression and radiation significantly suppressed the growth of HeLa xenograft (NS: not significant; **: $P<0.01$; ***: $P<0.001)$; (D) combination of miR-2I8 overexpression and radiation inhibited the expression of $\mathrm{Ki} 67$ and induced more cleaved caspase 3. 


\section{Discussion}

Generally, the squamous subtype accounted for more than $80 \%$ of all cervical cancer cases and was quite sensitive to radiation, while the adneocarcinoma and some other rare subtypes were not $[9,11]$. Unfortunately, several patients (especially those with local or distant metastasis) presented resistance to radiotherapy and usually obtained an unsatisfied outcome [7]. Therefore, how to eliminate radiation resistance was crucial for cervical cancer treatment, and one potent strategy was to develop new drugs to improve the radiosensitivity of tumor cells.

In the past decade, a large body of researches has demonstrated that microRNAs were involved in the regulation of cellular radiosensitivity. In lung cancer cells, upregulating the let-7 family increased cellular radiosensitivity via control of RAS and DNA damage repair genes [12]. In another study, miR-521 resensitized prostate cancer cells to radiation through modulating the CSA protein [13]. On the contrary, some microRNAs were also proved to be oncomiRs, which can induce radioresistance and promote cellular proliferation, migration and invasion. In gastric cancer cells, miR-221/222 could directly decrease the expression of PTEN and induce cellular resistance to radiation [14].

As we previously reported, miR-218 was frequent lost in human cervical cancer, which was correlated with tumor progression and poor prognosis [15]. Thus, we investigated whether restoration of miR-218 could improve the effects of radiotherapy in cervical cancer. In vitro, we demonstrated that abundant miR-218 could significantly increase cellular sensitivity to radiotherapy via enhancing the radiation associated apoptosis. In the nude mice model, combination of miR-218 overexpression and radiation achieved much better effects on suppressing the tumor growth. Moreover, in a panel of primary cultured human cervical cancer cells, we proved that tumors with abundant miR-218 were more sensitive to radiation. Our findings indicated that restoration of miR-218 could be a potent approach to improve the effects of radiotherapy in cervical cancer.

In vitro and in vivo, miR-218 overexpression significantly induced radiation associated apoptosis, accompanied with the accumulation of cleaved caspase 3 and cleaved PARP. Similar to our results, miR-218 was also proved to induce apoptosis via targeting NF-KB and BMI 1 signaling pathways in glioma and colon cancer $[16,17]$.

For the time being, several microRNAs are under evaluation in clinical trials as a novel type of drugs. SPC3649 (a miR-122 antagonist, NCT01872936), is used to treat chronic infection of Hepatitis $C$ in a phase II clinical trial [18]. And another phase I trial is evaluating the functions of MRX34 (miR-34 mimics, NCT01829971) in patients with primary liver cancer and other solid tumors [19].

In summary, we demonstrated that miR-218 resensitized cervical cancer to radiotherapy via enhancing apoptosis. In addition, miR-218 could predict the radiosensitivity of cervical cancer patients. Based on these findings, we propose combining miR-218 supplement and radiotherapy to be a novel treatment for cervical cancer, especially in the patients with loss of miR-218.

\section{Acknowledgments}

Our project was supported by grants to Yu Jinjin from Wuxi Science and Technology Bureau (No. CSE01N1113) and to Wang Yuan from the Affiliated Hospital of Jiangnan University (No. SY201305).

\section{Competing Interests}

The authors have declared that no competing interest exists.

\section{References}

1. Jemal A, Bray F, Center MM, Ferlay J, Ward E, Forman D. Global cancer statistics. CA Cancer J Clin. 2011; 61: 69-90.

2. Ferlay J, Shin HR, Bray F, Forman D, Mathers C, Parkin DM. Estimates of worldwide burden of cancer in 2008: GLOBOCAN 2008. Int J Cancer. 2011; 127: 2893-917.

3. Zhao FH, Hu SY, Zhang SW, Chen WQ, Qiao YL. [Cervical cancer mortality in $2004-$ 2005 and changes during last 30 years in China]. Zhonghua Yu Fang Yi Xue Za Zhi. 2010; 44: 408-12.

4. National Office for Cancer Prevention and Control N, Central Cancer Registry DPaC, Health BMo. Chinese Cancer; Registry Annual Report 2008. Beijing: Military Medical Science Press. 2009.

5. Shi JF, Canfell K, Lew JB, Qiao YL. The burden of cervical cancer in China: synthesis of the evidence. Int J Cancer. 2011; 130: 641-52

6. Moore DH. Cervical cancer. Obstet Gynecol. 2006; 107: 1152-61.

7. Rogers L, Siu SS, Luesley D, Bryant A, Dickinson HO. Radiotherapy and chemoradiation after surgery for early cervical cancer. Cochrane Database Syst Rev. 2012; 5: CD007583.

8. Nakano T, Kato S, Ohno T, Tsujii H, Sato S, Fukuhisa K, et al. Long-term results of high-dose rate intracavitary brachytherapy for squamous cell carcinoma of the uterine cervix. Cancer. 2005; 103: 92-101.

9. Powell ME. Modern radiotherapy and cervical cancer. Int J Gynecol Cancer. 2010; 20: S49-51.

10. Tie J, Pan Y, Zhao L, Wu K, Liu J, Sun S, et al. MiR-218 inhibits invasion and metastasis of gastric cancer by targeting the Robo1 receptor. PLoS Genet. 2010; 6: e1000879.

11. Gien LT, Beauchemin MC, Thomas G. Adenocarcinoma: a unique cervical cancer. Gynecol Oncol. 2010; 116: 140-6.

12. Weidhaas JB, Babar I, Nallur SM, Trang P, Roush S, Boehm M, et al. MicroRNAs as potential agents to alter resistance to cytotoxic anticancer therapy. Cancer Res. 2007; 67: 11111-6.

13. Josson S, Sung SY, Lao K, Chung LW, Johnstone PA. Radiation modulation of microRNA in prostate cancer cell lines. Prostate. 2008; 68: 1599-606.

14. Chun-Zhi Z, Lei H, An-Ling Z, Yan-Chao F, Xiao Y, Guang-Xiu W, et al. MicroRNA-221 and microRNA-222 regulate gastric carcinoma cell proliferation and radioresistance by targeting PTEN. BMC Cancer. 2010; 10: 367.

15. Yu J, Wang $Y$, Dong R, Huang X, Ding S, Qiu H. Circulating microRNA-218 was reduced in cervical cancer and correlated with tumor invasion. J Cancer Res Clin Oncol. 2012; 138: 671-4.

16. Gao C, Zhang Z, Liu W, Xiao S, Gu W, Lu H. Reduced microRNA-218 expression is associated with high nuclear factor kappa B activation in gastric cancer. Cancer. 2009; 116: 41-9.

17. He X, Dong $Y$, Wu CW, Zhao Z, Ng SS, Chan FK, et al. MicroRNA-218 inhibits cell cycle progression and promotes apoptosis in colon cancer by downregulating BMI1 polycomb ring finger oncogene. Mol Med. 2012; 18: 1491-8.

18. [Internet] ClinicalTrials.gov. Miravirsen in Combination With Telaprevir and Ribavirin in Null Responder to Pegylated-Interferon Alpha Plus Ribavirin Subjects With Chronic Hepatitis C Virus Infection. http://clinicaltrials.gov/ ct2/show/NCT01872936?term=NCT01872936\&rank=1.

19. [Internet] ClinicalTrials.gov. A Multicenter Phase I Study of MRX34, MicroRNA miR-RX34 Liposome Injectable Suspension. http://clinicaltrials.gov/ ct2/show/NCT01829971?term=NCT01829971\&rank=1 